\title{
After a Disaster: Lessons in Survey Methodology from Hurricane Katrina
}

\author{
Tammy L. Henderson • Maria Sirois · Angela Chia-Chen Chen • \\ Christopher Airriess - David A. Swanson - David Banks
}

Received: 6 February 2007/ Accepted: 21 June 2007/Published online: 7 November 2008

(C) Springer Science+Business Media B.V. 2008

\begin{abstract}
In 2005, the National Science Foundation funded a number of projects to study the impact of Hurricane Katrina. The current article provides an overview of several research approaches used to conduct post-Katrina research. Each method had some advantages and disadvantages. The post-disaster context meant that experience from traditional survey methods often did not apply. Comparisons of advantages and disadvantages associated with each sampling method serve to
\end{abstract}

\section{T. L. Henderson $(\bowtie)$}

Human Development and Family Science, Oklahoma State University, 233 HES, Stillwater, OK 74078-6122, USA

e-mail: tammy.henderson@okstate.edu

\section{Sirois}

Department of Biostatistics, School of Public Health and Tropical Medicine, Tulane University, New Orleans, Louisiana, USA

A. C.-C. Chen

College of Nursing and Healthcare Innovation, Arizona State University, 500 N. 3rd Street, Phoenix, AZ 85004, USA

C. Airriess

Department of Geography, Ball State University, Muncie, IN 47306, USA

e-mail: cairries@bsu.edu

\section{A. Swanson}

Department of Sociology, University of California Riverside, Riverside, CA 92521, USA e-mail: David.swanson@ucr.edu

D. Banks

Institute of Statistics and Decision Sciences, Duke University, Durham, NC 27708, USA

e-mail: banks@stat.duke.edu 
inform future post-disaster research and illuminate the limits of classical research methods.

Keywords Disaster research · Short-form enumeration · Long-form sample survey · Stratified random sampling · Convenience sampling ·

Purposive sampling

\section{Introduction}

The disorder and crisis that followed Hurricane Katrina underscores the need for improved communications and planning, accurate personal, health, legal, and financial information, sufficient transportation, immediate housing options, and access to mental and physical health providers to respond to extant and longer term needs for families facings natural disasters (Brodie et al. 2006; Gibson and Hayunga 2006). These needs become even more vital as the response effort moves beyond rescue and into the relief and recovery phases. The relief and recovery phase determines resource allocation, targeted aid, and long-range planning. Likewise, the acquisition of traditional sources of research findings through the use of surveys, questionnaires, and assessments that are administered via telephone and face-to-face interviews is challenged by a disaster-whether the research occurs before, during or after the disaster. Otherwise viewed as basic, research considerations (i.e., protecting research quality and maintaining sufficient sample size) become much more challenging in the midst of a crisis or natural disaster (Norris 2005).

Determining the best sampling strategy is another critical factor for scientists to ponder. Previously, researchers have used clinical, convenience, purposive, and random samples in disaster studies (Norris 2005). If the affected group was sufficiently small, the sample often became, in effect, a census (Norris 2005). Similarly, in this article, we explore four different sampling strategies that were applied after Hurricane Katrina: (a) an approach much like that used in the 2000 census in which both a complete "short form" enumeration and "long form" sample survey were conducted at the epicenter of Katrina's impact on the Mississippi gulf coast; (b) a stratified random sample, using three interview modes and a frame that consisted of all people resident in New Orleans residents on the day before Hurricane Katrina struck; (c) convenience sampling, undertaken at senior centers, senior housing, participants' homes, and FEMA relief trailer communities; and (d) purposive sampling, recruiting a targeted sample in identified census tracts by collaborating with faith-based organizations and service providers from the study area and a non-profit social organization in Houston. None of these methods dominates the others; each has its own role and value. In fact, because conventional social science approaches to designing surveys may not apply, or may be misleading in times of disasters, we describe techniques used to conduct research after the impact of Katrina and its immediate aftermath. In so doing, we discuss the challenges faced in conducting disaster research and the approaches used to address these challenges to support others managing future efforts focused on disaster research. 


\section{Survey Methods in the Katrina Context}

\section{The Long Form Sample and the Short Form Census}

As one of several post-Katrina research projects funded by the National Science Foundation, the recipients of SGER Grant \#0555136 conducted a study that: (a) gathered pre- and post-Katrina information on housing and population from 573 targeted census blocks at the epicenter of Katrina's impact on the Mississippi gulf coast that the 2000 census showed as containing people; and (b) employed a random start, systematic selection, cluster sample targeting 126 of these 573 blocks for administration of a 105-item questionnaire, such that at least 350 completed questionnaires would be obtained. The 105-item questionnaire was designed to collect retrospective information on the roles that social and kinship networks played in determining respondents' success (i.e., the capacity for respondents to sustain their physical and emotion needs after Hurricane Katrina).

This effort entailed a number of operational challenges, but the team was successful in collecting "short form" data from 346 of the targeted 573 blocks and "long form" data comprised of 400 completed surveys collected from 71 blocks, 68 of which were from the 126 blocks targeted for "long form" data collection and three of which were from "short form" blocks erroneously canvassed. The data for the 346 blocks represent a complete enumeration of all housing, permanent and temporary, a determination of their condition (habitable, damaged, or destroyed) and occupancy status. As such, it enables a block-by-block comparison of the preKatrina and post-Katrina housing and population in terms of traditional U. S. Census Bureau concepts and definitions.

\section{Data Collection Details}

The study population consisted of persons residing within Hancock and Harrison counties on the Mississippi gulf coast within a time period of approximately 46 months after Hurricane Katrina struck. The study area is defined by selected blocks within Census Tracts 0302 and 0301 in Hancock County and tracts 0300, 0290, 0280, and 0270 in Harrison County (See Table 1 for additional details). Consistent with the practices of the U.S. Census Bureau's decennial collection, the project administered a "long form" to a sample of residents. This was done during a week long period in early January of 2006, 4 months after Katrina stuck. The short form was used to survey all residents; much of this work was done during a weeklong period in the middle of March of 2006, about 6 months after Katrina struck. During the initial field work, the team found that two blocks in Tract 0300 were actually part of two other blocks rather than distinct blocks. Results for these two blocks, 1038 and 2068 were merged into the blocks of which they were a part, 1036 and 2067, respectively. This yielded 151 blocks in tract 0300 and 573 blocks in the entire study area. Following the strategy of the U.S. Census Bureau in its collection of decennial census data, the census team used a "long form" sample to collect data to address the research hypotheses and a complete enumeration to obtain postKatrina information to compare with 2000 census data. The following section 
Table 1 Hurricane Katrina-census study

\begin{tabular}{lll}
\hline County & $\begin{array}{l}\text { Census } \\
\text { tracks }\end{array}$ & Description \\
\end{tabular}
Hancock $0302 \quad \begin{gathered}69 \text { blocks from block } \\ \text { groups } 1 \text { and } 2\end{gathered}$

Waveland and, MS, and environs

Hancock 0301

Harrison 0300

Harrison 0300

Harrison 0290

Harrison 0280
124 blocks from block groups $1,2,3,4$, and 5

Bay St. Louis, MS, and environs

153 blocks from block groups 1 and 2

Pass Christian, MS, and environs

153 blocks from block groups 1 and 2

Pass Christian, MS, and environs

85 blocks from block groups 1 and 2

Pass Christian, MS, and environs

74 blocks from block groups 1, 2, 3, 4, and 5

Long Beach, MS, Pass Christian, MS, and environs
Tract used for training and the pilot study

The random selection cluster started with the 8th block and continued through 6 selections

Sometimes the blocks adjacent to the cluster were sampled because the initially selected block had few residents; this process was used for training and pilot test purposes

Resulted in 18 sample blocks for a total of 39 blocks

Canvassed 18 of 18 blocks in the primary sample; no supplemental blocks

Sampled 18 of 21 blocks in the primary sample; no supplemental blocks

Before interviews began and with a random start at the 3rd block in Tract 0201 at every 20th block that was listed immediately before and after the selected block-the "cluster." The result was 7 cluster selections and 21 blocks

Canvassed 32 blocks from supplemented sample; 3 blocks canvassed in error

Two blocks in Tract 0300 were part of two other blocks and were not distinct blocks

Merged blocks 1038 and 2068 into part of blocks 1036 and 2067, respectively; therefore, there were only 55 blocks in Harrison County

Canvassed 19 of 21 blocks in the primary sample; 6 blocks in the supplemental sample

Canvassed 32 blocks from the supplemented sample; canvassed 3 block in error

Two blocks in Tract 0300 were part of two other blocks; they were not distinct blocks

Merged blocks 1038 and 2068 into the blocks that were a part of blocks 1036 and 2067, respectively. Therefore, there were only 55 blocks in Harrison County

Canvassed 19 of 21 blocks in the primary sample and 6 blocks in the supplemental sample

Canvassed 32 blocks from the supplemented sample; canvassed 3 block in error

Canvassed 8 of 12 blocks in the primary sample; canvassed 6 blocks in the supplemental sample

Canvassed 32 blocks from the supplemented sample; canvassed 3 in error. Resulted in 94 blocks

Canvassed 12 of 12 blocks in the primary sample; canvassed 12 blocks from the supplemented sample

Canvassed 32 blocks from the supplemented sample; canvassed 3 blocks in error 
Table 1 continued

\begin{tabular}{llll}
\hline County & $\begin{array}{c}\text { Census } \\
\text { tracks }\end{array}$ & Description & Sampling procedures \\
\hline Harrison & 0270 & $\begin{array}{c}70 \text { blocks from block } \\
\text { groups 1, 2, 3, and } 4 \\
\text { Long Beach, MS, and } \\
\text { environs }\end{array}$ & $\begin{array}{c}\text { Canvassed } 8 \text { blocks in the supplemental sample } \\
\text { This was augmented by 32 canvassed blocks from the } \\
\text { supplemented sample and three blocks canvassed by } \\
\text { error }\end{array}$ \\
\hline
\end{tabular}

outlines strategies used to manage survey errors to administer "long" and "short" form surveys.

Long Form Sample Dillman (2000) described four sources of survey error and the related consequences: (1) sampling error; (2) coverage error; (3) measurement error; and (4) non-response error. Sampling error has two components, variation (in the population) and sample size (Kish 1965), which was addressed by maximizing sample size and remaining true to the principles of scientific inquiry. Although the context of a disaster alone provides unforeseeable challenges, the combination of a disaster, funding constraints, and time limitations further test a researcher's capacity to minimize sampling errors. Thus, to minimize sampling errors in the face of these constraints and limitations, the team employed using a random start, systematic selection, cluster sample with the census-defined blocks as the primary sampling units. This team's design was well-suited for collecting data from the study population because it: (a) provided the only feasible sample frame to use with this population; (b) used a cost-effective process; (c) characterized a data collection process that could be used by an inexperienced research team member (Swanson 1997; Swanson 1982a, b, c, 1983a, b; Swanson et al. 1990); and (d) allowed maps and related data based on the 2000 census to be immediately available to the team via the Center for Population Studies at the University of Mississippi.

The random start, systematic selection of clustered "census blocks" also was used to control for coverage error. The sample frame consisted of all the blocks in the study area identified in the 2000 census population $(N=573)$ and the blocks were listed in numerical order within each of the six census tracts in the study area in Hancock and Harrison Counties. For Hancock County, before the interviewing process and with a random start at the third block in tract 0301, every 20th block was selected and every block listed immediately before and immediately after the selected block (i.e., the "cluster"). This yielded seven cluster selections and 21 blocks in Tract 0301. Tract 0302 was used to train staff and to conduct the pilot study. Because of the lack of people in the blocks initially selected, in a couple of cases, adjacent blocks to the cluster were sampled in Tract 0302. Similar strategies were used for tracts 0300, 0290, 0280, and 0270. In summary, 39 blocks made up the primary sample from Hancock County and 57 in Harrison County, which should have created 96 blocks for the entire study area. With the two blocks that were merged in Tract 0300, however, the entire study area yielded a primary sample of 94 blocks. Because of the uncertainty about how many of these blocks would actually 
contain residents, a supplemental sample of 32 additional blocks was drawn to help ensure that an adequate number of completed questionnaires would be obtained (the target was 350 completed questionnaires).

Because the pre-Katrina population no longer resided in many of the study blocks to guarantee a sufficient sample size, the research team made several decisions during the period of data collection in January of 2006. They had to reduce the number of days used to canvass the sample area-nine blocks in the primary sample were not surveyed. The shortened time spent in the field allowed the team to devote all available team members to clearing callbacks, picking up completed forms, and leaving "mail-back" packets. The decision to use the supplemental sample was made tract by tract by the respective teams; this strategic was used to manage coverage and sampling error. For instance, they obtained a supplemental sample from Tracts 0270 through 0301 by surveying the block midway between each 20 th block and two blocks listed to either side of it. The result of these efforts was that: (a) 85 of 94 blocks in the primary sample areas were canvassed (including the two blocks in Tract 0300 that were found to be part of two other blocks); (b) 32 of the 32 blocks the supplemental sample were canvassed; and (c) three blocks were canvassed from the "short form" set by error. From all of this work in early January, usable long form data $(n=400)$ were obtained from people who resided in 71 of these blocks.

To reduce measurement error and non-response error (Dillman 2000), the questionnaire and interview protocol were revised many times by the research team and others after pre-testing was completed in selected blocks from Tract 0302, which had a variety of conditions. This tract covered a range of conditions experienced on the Mississippi Gulf Coast and contained single and multiple housing units, as well as temporary housing units. Participants resided in a variety of housing situations, such as trailers on or near the foundations of former houses to apartment units with power, water, and telephones. According to the pre-test, the questionnaire did not need any major changes; however, the interview protocols were revised and the decision was made not to pay research participants. The pretesting served to refine the processes or procedures needed to train, support, and maintain the safety and health of interviewers. The team was comprised of interviewers trained to deal with members of the distressed population (Hummer et al. 2005). Key members of the research team also were experienced in addressing distressed populations of Hurricane Katrina and were familiar with the Mississippi gulf coast; these qualities proved important in contacting and interviewing persons who were directly influenced by Hurricane Katrina.

In addition to the pre-tests, training, and using interviewers familiar with the area and distressed populations, research team members were required to make daily check-ins, maintain rigorous records of canvassed blocks and interview attempts, and multiple call backs were made to seemingly occupied areas. "Mail back" procedures were used to secure completed questionnaires from addresses where residents had not completed surveys and where no record of refusal existed. These efforts served to enhance the collection of quality "long form" data and reduce the four sources of survey error given time and budget constraints. In the end, the team collected 400 completed surveys from people residing in 71 of the 117 blocks canvassed for the "long form," to include three blocks erroneously canvassed from 
the "short form" set, and the employment of 23 "drop-off/mail-back" surveys and 140 "mail-out/mail-back" packets.

\section{"Short Form" Data}

The "short-form" surveys and interview protocols also were constructed to minimize measurement error and non-response bias. These research tools, just like the "long-form" surveys, went through revisions and reviews by team members and others. Pre-tests were conducted using 16 randomly selected blocks from Tract 0302 in Bay St. Louis, Mississippi. These 16 blocks covered a variety of conditions that were caused by Hurricane Katrina's storm or water surge that damaged homes and buildings. The 16 blocks in Tract 0302 contained single and multiple housing units (i.e., apartments and condominiums) and residents in trailers on or near the foundations of former houses to apartment units with power, water, and telephones. Based on the pre-test results, no major changes were needed in the questionnaire. The interview protocols were revised and field procedures were refined and used to train interviewers. The revised field procedures also were designed to protect and support interviewers in the field. Members who had experience with on the ground work on the Mississippi Gulf Coast were invaluable and able to gain trust and rapport with study participants (Hummer et al. 2005).

Short form data were also collected from the blocks targeted for the "long form" sample. These data were collected in January of 2006. The remaining short form data were largely obtained during the collection period in March of 2006. Thus, with 117 blocks canvassed for the long form data collection, an additional 229 were canvassed solely for the collection of short form data.

Summary Having inaccurate maps of census blocks, a lack of people residing in the sampling areas, and addressing measurement and non-response errors when conducting disaster research were among the challenges faced for the "long- and short form" census study. The team revised and pre-tested the instrument to reduce measurement and non-response error. Some of the most advantageous processes used to conduct this study were using (a) a sample block to train the research team, (b) replacement sampling in unoccupied areas to control for coverage area, and (c) merging sampling blocks to accurate identify the sampling area. Additionally, members of the research team were familiar with the Mississippi gulf coast area, providing the team with contacts and strengthening the ability to interview individuals from the area.

\section{Stratified Random Sample}

In December 2005, the National Science Foundation funded Grant Number REC0555934 to conduct research on a stratified random sample of people who had resided in New Orleans, Louisiana before Hurricane Katrina. The purpose was to identify the factors that led people to evacuate before Katrina struck and discover what variables affected people's post-disaster experience. The answers to these 
research questions may guide future planning for evacuations both in determining what resources are needed to facilitate the decision to evacuate and also what kinds of support are needed to ensure a short, orderly evacuation or displaced experience.

The frame for the survey was the non-institutionalized adult population who were residents of New Orleans on the day before Hurricane Katrina struck and unleashed high winds, high waters from breached levees, and high mortality rates. In a postdisaster setting, such as Hurricane Katrina, the study population included many people who no longer lived in New Orleans, and perhaps no longer maintained a permanent address in the city. At the time of the interview, some residents were present because either they returned after evacuating or they never left the city. Former residents were absent mostly because they evacuated and remained outside of the city on a temporary or permanent basis.

A multi-modal survey approach was taken to capture these groups: the group of pre-Katrina New Orleans residents who were present in the city during the survey period, and the group absent from the city after Hurricane Katrina. The survey had three modes: an in-person interview, a telephone interview for landline phones in New Orleans and Baton Rouge Metropolitan Statistical Areas (MSAs), and a telephone interview for cell phone numbers issued to New Orleans. The first mode was aimed at people who had returned to the city or who had not left - the first group described above. The second mode was aimed both at people who returned to the city (the present population of New Orleans) and those who were forced to relocate to Baton Rouge after the storm (the absent population). In the third mode, cell phone surveys sought to capture residents who were no longer in New Orleans (the absent population).

\section{Mode 1-In-person Interviews}

The initial plan for this mode was to stratify the in-person interviews on both income and house elevation. Because elevation was so strongly associated with income, the project was modified to just two strata: flooded and non-flooded areas. This determination was initially based on the most readily available flood maps and data, which, in the planning stage, depicted generally flooded and non-flooded areas. More precise data showing flooding status by street became available at a later time. These data were not found to be useful because sometimes the flooding was highly localized with a small number of non-flooded streets interspersed in areas of flooded streets. By using the less precise data, the stratified random sample team was able classify each census tract as mostly flooded or non-flooded. The map in Fig. 1 shows the strata: light gray shows census tracts that were primarily flooded; dark gray shows tracts that were primarily dry.

The sampling protocol was to first generate physical points that represented a geographic coordinate at random locations on a street map of the census tract, with the number of dots determined by the flooding status. Then the interviewer went to each point, and chose the nearest house. If there was a person at that house, then the interviewer attempted to complete a questionnaire; if not, the interviewer moved on to the next location. 


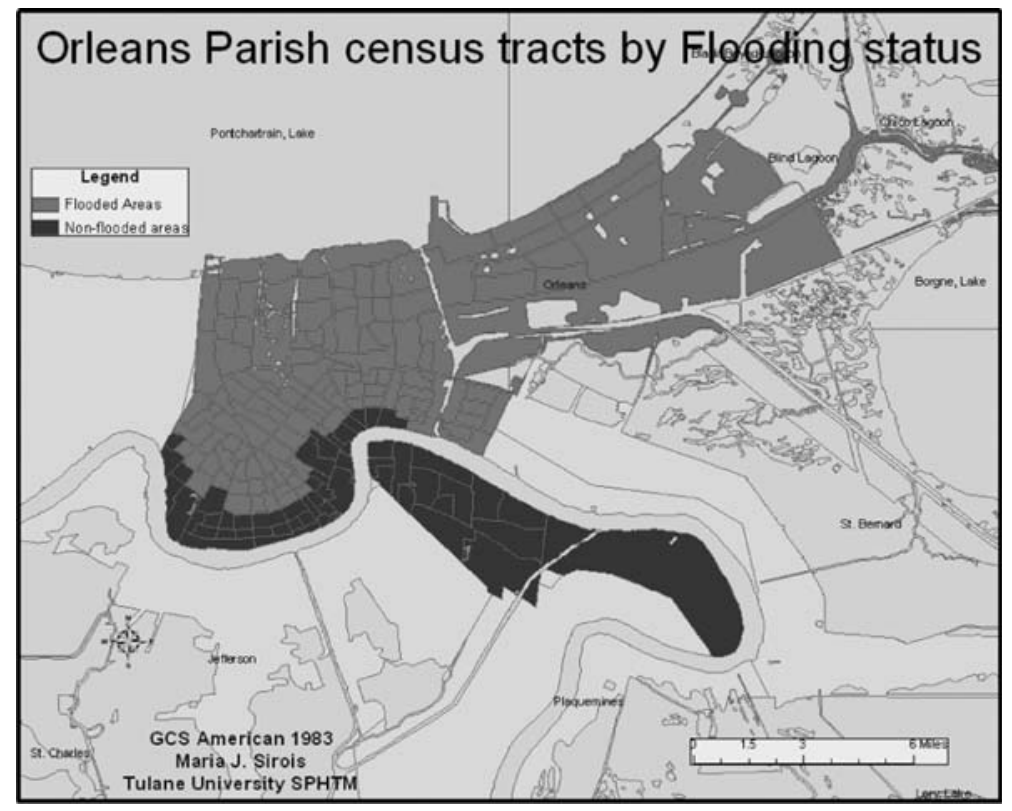

Fig. 1 Orleans parish census tracts by flooding status

One advantage of the in-person mode was the high response rate achieved (i.e., 77\% according to the American Association for Public Research [AAPOR] 2004) formula for response rate 5; (Oregon Survey Research Laboratory 2007; Public Opinion Laboratory 2007). Study participants were interested in the research and very few of the people approached declined to do the interview. Most refusals were because of time constraints faced by the interviewee. The response rates of the present study are similar to those demonstrated in classic studies comparing survey modes, showing that in-person surveys tend to get higher response rates (Groves et al. 2004).

\section{Modes 2 and 3 Landline and Cell Phone Interviews}

For the two telephone surveys, based on landlines and cell phones, it was not possible to stratify on flooding status since the exchange code locations correspond neither to census tracts nor to spatially referenced points on a map. The landline surveys for New Orleans area telephone exchanges represented something close to a random sample of the post-Katrina residents, while the landline surveys in the Baton Rouge MSA and the cell phone surveys represented the now absent pre-Katrina residents. The respective response rates for the landline and cell phone surveys were $39 \%$ and $35 \%$, which is reasonable given these data were collected after both a natural and technological disaster and in the early months of a longer term crisis. 


\section{Research Concerns}

In addition to the modest response rates from telephone interviews, the research team encountered many operational difficulties in conducting the survey in Mode 1. The first research challenge was safety, including the possibility of criminal hazards; there were potential physical, chemical, and biological hazards. In the early phase of the study, there were concerns about disease; these concerns were largely obviated by the time fieldwork began in January. At one point, the primary interviewer was in close proximity to the blast zone from an exploding transformer. The research team was fortunate that the lead interviewer who had military training, and Hazardous Waste Operations and Emergency Response (HAZWOPER) and First Responder certifications. Difficulty contacting people, especially in the most devastated areas, represented a second research challenge. Since the interviews were conducted over the course of 4 months, sample bias was introduced by the increasing ease of finding interviewees as portions of New Orleans residents returned. Although biases are always difficult to quantify, it seemed clear that the people who returned, during this period, had greater economic resources. This team found a greater number of higher income residents and homeowners than one would expect from a random sample, based on pre-Katrina data from the U.S. Census. Aging women returned to the affected area, which may reflect their greater availability during the day to receive interviewers, or perhaps a stronger drive to return to their homes than other demographic groups, or both.

A third research problem was in the assignment of standard disposition codes (AAPOR 2004). Some houses appeared at first to be vacant, but close examination showed signs of rebuilding or even occupancy. Similarly, it was difficult to tell if some FEMA trailers were in service and whether anyone was living in them, as they were observed in various stages of being hooked up to utilities.

A fourth problem was navigation and logistics. In some areas, locating the randomly generated point was difficult since pre-Katrina street signs and landmarks were missing. Similarly, the interviewers had to carry spare fuel, food and water, medical supplies, and maintain a regular communications link. For the Katrina situation, careful planning was sufficient, but researchers expected that in other disaster surveys, as might arise from tsunamis or earthquakes, these problems could be more serious. Interviewers and research staff should be prepared to be selfsufficient and have a working knowledge of the NIMS (National Incident Management System) or ICS (Incident Command System) management. The degree of self-sufficiency required depends on the severity of the disaster and phase in which the data is collected.

A fifth problem was purely administrative. The plan originally approved by the Office of Sponsored Research at Tulane University ensured that respondents would be paid $\$ 50$ for their time; additionally, the university's Institutional Review Board stipulated that Social Security Numbers (SSN) not be collected. But when it was time to pay, the Accounting Office at Tulane University balked, on the grounds that checks could not be sent without an SSN. Although, there eventually was a resolution that respected the needs of all parties, this administrative anecdote demonstrates the inconsistent decision-making that can occur in an institutional 
setting after a disaster. University organizational infrastructure and human resources operating within that system were affected by the hurricane, resulting in a fragmented, short-staffed and only quasi-operational system.

Landline and Cell Phone Interviews Traditionally, a main concern about bias in telephone surveys is they undercount people without telephones, although only an estimated $2 \%$ of American households do not have telephones; there are also concerns about demographic differences between households with cell phones and those solely with landline telephones (Blumberg et al. 2006). In the post-Katrina context, additional biases may occur because some people have let their New Orleans cell phone number lapse before the telephone surveys began. The sample would thus have fewer participants from lower income backgrounds because people with fewer resources may be more likely to let their cell phone contracts expire or lapse. In addition, the landline survey did not begin until 1.5 months after the field interviews to ensure that the questionnaire was capable of capturing the phenomena being studied and flexible. The cell phone survey did not start until the 3rd month. Thus, these systematic differences, due to trends over time in the returning population that affected who among the New Orleans population were contacted to participant in the study. Trends over time may threaten the internal longitudinal consistency of the study (Campbell and Stanley 1963) and could create subtle kinds of bias. A sophisticated statistical analysis may be able to adjust for this, since the questionnaire obtains information on when a respondent returned and thus became available for an in-person interview. Unfortunately, the survey did not capture information on cell phone ownership, which would enable modeling and correction for non-cell phone households.

The main obstacle in the telephone interview modes was that the call center initially refused to perform the cell phone interviews, which would have destroyed the original sampling plan and prevented contact with an important part of the frame. Since cell phone users are charged by the minute (details vary according to the contract), the call center administration feared interviews would impose an undue burden and antagonize potential respondents. Also, some guidelines produced by telephone survey experts at the Cell Phone Summit oppose cell phone surveys on grounds of both the burden and the fact that the population of cell phone users is different from the general population. Other guidelines encourage wireless substitution, as the exclusion leaves an important cohort of the population out of a study (Lavrakas and Shuttles 2005). This team eventually persuaded the call center to attempt a 1-day pilot of cell phone interviews; these worked splendidly. No one complained about the charge for their minutes. Based on pilot data, the call center agreed to perform a full round of cell phone interviews and the response rate was essentially the same for the landline users.

Regardless of the analytic issues with telephone surveys in a post-disaster setting, there was increased efficiency and safety concerns for the investigative staff. Additionally, the combination of cell phone surveys as a supplement to in-person and landline telephone interviews seems like an essential component of any post-disaster survey plan. Otherwise, the interviewers will necessarily miss the entire cohort of 
long-term evacuees. By using a multi-modal sampling strategy, we were able to achieve a balance of cost and time efficiency, staff safety and an overall acceptable response rate.

Summary Because the elevation of the homes was highly correlated to income of residents, the stratified random sample team had to use another stratum: flooded versus non-flooded. A lower response rate should be expected when conducting disaster research. In addition to the risk of physical health concerns and potential assaults, biological and chemical hazards increased the safety concerns for this team. Having a sufficient sample size was threatened because the team found it difficult to contact potential study participants. A larger number of homeowners or higher income residents agreed to participate in the study, increasing the concern with sampling bias. Missing landmarks and street signs made the entire study process difficult. Paying participants a small cash incentive was an administrative challenge because the IRB and Accounting Office had different requirements.

Despite these challenges, this team used less precise data to create their stratified sample. They decided to conduct a cell phone study, given the problems with trying to identify participants in the affected area. In addition, they found it useful to have a research team member who was certified as a First Responder and who had military and Hazardous Waste Operations and Emergency Response (HAZWOPER) training. They recommended having someone on the research team with NIMS or ICS training.

\section{Convenience Sampling}

The National Science Foundation funded a project (HSD \#0650909) to examine how aging adults made decisions and functioned in the aftermath of Hurricane Katrina. The study sample included displaced persons and long-term residents of Baton Rouge and the surrounding region who fit into these three categories: (a) aging adults who were 60 years or older; (b) grandparents 50 years or older who were parenting their grandchildren; and (c) caregivers of an aging adult who was 60 years or older. Using the life course perspective (Elder 1977) and the ecological model of human development (Bronfenbrenner 1986), this research team examined the functioning of aging families in the aftermath of a natural disaster. Personal interviews with a series of structured close-ended questions was used to elicit information in five areas: (a) demographic information; (b) health and psychosocial functioning; (c) reliance on family members, friends, and community services; (f) family decision-making; and (e) family functioning.

The primary investigators, well versed in quantitative and qualitative methods, also used open-ended questions regarding participants' personal histories, family relationships, evacuation narratives, and social and historical contexts. The two sampling groups_-displaced aging adults from New Orleans and the surrounding areas and long-term residents of Baton Rouge and the surrounding areas-were asked to take pictures in order to capture their lived experiences, which required a Media Release Form - an added human subject's protection for this study. Displaced aging 
adults also were asked to participate in a follow-up study to understand how their lives evolved after the interview and to gain some insights into how to conduct longitudinal studies following a natural disaster.

Although the current exploratory study involved multiple cases, it held two basic research characteristics: non-experimental design and convenience sampling. The close-ended questions were posed to both groups of participants only once, making this a cross-sectional analysis (Campbell and Stanley 1963). Because experimental controls, comparisons, and inferences are limited or absent, this design includes these threats to internal validity: (a) history-outside events may effect the dependent variable; (b) maturation-natural changes that occur as a result of the normal passage of time; (c) selection-an influence of nonrandom assignment or when random assignment fails to secure a balance sample; and (d) mortalitydifferences due to attrition rates. An interaction between selection and the event, in this case the aftermath of a disaster, represent the threats to external validity (Campbell and Stanley 1963).

Researchers may select study participants who are readily available-convenience sampling (Bailey 1994), such as a captive audience of participants living in trailer communities managed by the Federal Emergency Management Agency (FEMA, $n=4)$, senior centers or residential communities $(n=8)$, and churches $(n=3)$. Convenience sampling, an appropriate approach in a crisis, nonnormative situation, allowed researchers to engage in intensive data collection and acquire a specific sample size. This non-probability sampling technique eliminates researchers' capacity to generalize findings to other groups, limiting the implications of the study to the group studied. Convenience samples are used to conduct exploratory analyses, reduce research costs, conduct intensive analysis on small groups of individuals, and allow researchers to conduct large studies.

Consistent with convenience sampling, to identify potential study participants, introductory letters, biographical sketches, project abstract, flyers, and a copy of the Institutional Review Board Approval letter were mailed to faith-based institutions, aging agencies, and the local FEMA group between November 2005 and January 2006 (See Table 2). Each mailing was followed-up by telephone calls with the goal of meeting with potential collaborators. A few faith-based institutions and one state agency designed to meet the needs of older adults initially replied to the packets. Detailed record keeping (i.e., audit trail to provide participants with a small incentive-\$25 Wal-mart gift card and comply with IRB requirements, Excel files of contacts information for FEMA and other collaborators, tracking all modifications in the methods, revising and printer posters, flyers, and screening tools, and more) intensified the administration of the study focused on a natural crisis.

Plans were made to travel to Louisiana to pilot the surveys and reduce measurement error (Dillman 2000), and to meet with faith-based groups and aging agencies to gain their assistance in identifying participants. It took 2 months before these efforts resulted in scheduled interviews with participants at specific sites because collaborators were facing a disaster and some were victims of the disaster. Two primary investigators in another state; however, one primary investigator was a native of Louisiana, giving the research team greater entry. The convenience sample 
Table 2 Convenience sampling study administration

\begin{tabular}{|c|c|}
\hline Time frame & Activities \\
\hline $\begin{array}{l}\text { November- } \\
\text { December } 2005\end{array}$ & $\begin{array}{l}\text { Created survey packets with interviews, receipt and audit trail for Wal-Mart gift } \\
\text { cards, Consent Forms, and Medial Release Forms } \\
\text { Mailed introductory packets to aging agencies, faith-based institutions, and other } \\
\text { groups } \\
\text { Held telephone interviews of potential interviewers; received their certificate for } \\
\text { IRB training and resumes } \\
\text { Developed Training Packets for interviewers on the research team }\end{array}$ \\
\hline January 2006 & $\begin{array}{l}\text { Visited local agencies } \\
\text { Conducted pilot interviews with long-term resident and displaced persons and } \\
\text { modified instrument }\end{array}$ \\
\hline February 2006 & $\begin{array}{l}\text { Conducted interviews at various sites } \\
\text { Trained interviewers, visited FEMA and other agencies, modified flyers, and } \\
\text { created screening tool for collaborators and research team members } \\
\text { Modified, submitted, and received approval of the surveys by Virginia Tech's } \\
\text { Research Compliance Office. The resident survey was modified to include } \\
\text { perceptions about their community } \\
\text { Began entering SPSS data }\end{array}$ \\
\hline April 2006 & $\begin{array}{l}\text { Attended "Life After } 50 \text { Exро" to identify and screen potential study participants } \\
\text { Mailed introductory packets to various Lion's Club organizations in Baton Rouge } \\
\text { to recruit residents } \\
\text { Conducted interviews with displaced persons in various trailer communities and } \\
\text { within their homes, as well as with long-term Baton Rouge residents }\end{array}$ \\
\hline May-June 2006 & $\begin{array}{l}\text { Conducted interviews with displaced persons in various trailer communities and } \\
\text { with long-term residents in their homes or at senior centers } \\
\text { Began transcribing open-ended questions } \\
\text { Typed up notes from personal journals submitted by displaced aging adults and } \\
\text { conducted follow-up telephone interviews }\end{array}$ \\
\hline July 2007 & $\begin{array}{l}\text { Focused on data entry and transcription tasks } \\
\text { Analyzed personal journals submitted and conducted follow-up telephone } \\
\text { interviews } \\
\text { Moved project to Oklahoma State University }\end{array}$ \\
\hline $\begin{array}{l}\text { August 2006-March } \\
2007\end{array}$ & $\begin{array}{l}\text { Transcribed and verified open-ended questions } \\
\text { Cleaned SPSS data and analyzed follow-up interviews } \\
\text { Began quantitative data analyze; outlined final report, which was submitted in } \\
\quad \text { March } 2007\end{array}$ \\
\hline
\end{tabular}

team interviewed 125 displaced aging adults from New Orleans and the surrounding areas between February and June 2006.

In addition, the primary investigators and interviewers attended the Life After 50 Expo held in Baton Rouge, LA in April 2006 to screen potential participants with a focus on long-term residents. Concern with identifying displaced aging adults may have blurred the primary investigators' awareness of "compassion fatigue" (Bride 2004; Leon et al. 1999; Roberts et al. 2003) by long-term aging residents of Baton Rouge and the surrounding areas. Compassion fatigue refers to the gradual decrease 
in empathy or compassion over time. It may be influenced by the dissemination of mass media stories and images of people who are suffering, such as images of starving children in Africa, the communities devastated by the Tsunami, and other horrific events. Over time people oppose or resist these horrific images. As the impact of emotional impressions declined, so does people's willingness to give also declines (Figley 2006).

Interviews with long-term residents of Baton Rouge largely took place in April to June, 9-10 months after Katrina made landfall. By this time, residents were less inclined to discuss the topic, introducing threats to internal validity, such as history and maturation (Campbell and Stanley 1963). Based on the findings from this project, long-term residents of Baton Rouge were challenged by the increased traffic, higher costs associated with housing, higher rates of crime, and the inconveniences of securing doctor and social service appointments. Media reports were ongoing and the influx of people, including the media disrupted the Baton Rouge community. On the one hand Baton Rouge residents felt a need to support their displaced neighbors from New Orleans; however, they too were experiencing some loss, some had actual damage done to their homes, and others had family members who were killed or sustained substantial losses.

Despite these factors, this team was able to interview 95 long-term residents of Baton Rouge and the surrounding areas by June 2006. In addition to over 400,000 people evacuating just prior to Katrina making landfall, East Baton Rouge Parish was among the 64 parishes that qualified for public or individual assistance from the Federal Emergency Management Agency (U.S. Department of Labor 2005). In consultation with NSF, resident interviews were ended in June to reduce sample bias due to history (Campbell and Stanley 1963).

Regardless of the advantage of convenience sampling there were added research challenges, which largely was an artifact of conducting research during a crisis. When conducting a study on aging adults displaced by Hurricane Katrina funded by the National Science Foundation, researchers found convenience sampling was difficult to manage. These challenges were in three areas: (a) research collaborations caused additional stress for agencies and faith-based institutions, (b) clearance authorizations influenced interviews with residents living in FEMA trailers, and (c) intensive administrative tasks were heightened.

\section{Research Collaborations}

The primary collaborators, individuals directly involved in the crisis intervention of Hurricane Katrina, included the Governor's Office on Elderly Affairs (GOEA), East Baton Rouge Council on Aging, the Council on Aging of St. Tammany Parish, New Orleans Council on Aging, The Archdiocese of New Orleans, and FEMA. Oftentimes, our collaborators posted flyers, screened participants, scheduled interviews, and identified other collaborators or potential research participants. Some members of the GOEA and councils on aging were trained to and conducted interviews. East Baton Rouge Council on Aging, New Orleans Council on Aging, Shiloh Missionary Baptist Church, and the Archdiocese of New Orleans allowed interviews to be conducted at their facilities. These supports were not without challenges. 
Given the state of affairs, 5 months after Hurricane Katrina made landfall and the levees breached, faith-based organizations and aging agencies assisted in the research, but their ability to participate was limited. Many administrators were serving as caseworkers, referral agencies, and crisis managers along with their administrative roles, leaving little time for research. Councils on aging were overburdened by a loss of programs and funding sometimes coupled with the loss of personal property and family; saving lives and supporting displaced persons and local residents took priority over research findings that may or may not influence everyone's understanding of a natural disaster. Collaborative interactions took longer to complete because the offices were overburden by the disaster but they valued research and believed the data would be useful for recovery and preparedness purposes.

Hurricane Katrina also displaced employees of faith-based organizations, FEMA administrators and workers, and aging agencies. The Executive Director of New Orleans Council on Aging and local residents of New Orleans, lost 10 of 18 senior centers, a state-of-the-art dental van, and other resources (Durant et al. 2006). Some of these churches and agencies also served as temporary shelters and continued to support displaced aging adults, leaving little time or resources for full engagement in a research project. The immediate needs of displaced workers had to take priority over long-term outcomes related to research. Obtaining assistance with identifying participants in senior centers, senior housing units, FEMA trailer communities, and churches proved to be complicated but a necessary collaboration to expedite face-toface interviews.

\section{Clearance Challenges}

Unless an individual invited us to his or her home, the research team was required to obtain clearance to interview residents in FEMA trailer communities, a very involved process. To reduce delays in the data collection process and to adhere to policies set for trailer communities, FEMA consistently contacted their headquarters on our behalf to ensure that we followed all procedures and policies. They reviewed our file, which included a copy of our IRB, flyers, project description, surveys, and screening tool. In addition to the general clearance, a public relations person had to review and shadow our research team because pictures were included in the grant. Because the project included four different trailer communities and on-site FEMA officials changed on a regular basis, the research team had to make sure that FEMA recognized that clearance was previously given and indicted on each visit that the team was merely interviewing displaced aging adults within multiple trailer communities.

The strategies used to negotiate with FEMA were quite transparent and helpful to the research team. One primary investigator elected to meet with each administrative team at the trailer communities. This proved to be the most successful strategy in expediting clearance, obtaining participants who fit the study criteria and objectives, and building rapport with the participants, which resulted in a higher number of interviews. Additionally, safety concerns were reduced because FEMA had guards escort us to trailers if the participant wanted to be interviewed in their 
temporary home; guards were posted at community tents or trailers during the interview process. Some areas in select trailer communities were known for illegal activities, such as drugs, robberies, and physical assaults. FEMA, however, was able to keep other predators out of the trailer communities, and to generally maintain order by screening visitors who were not there to see specific persons.

\section{Intensive Administrative Tasks}

Administrative challenges included creating a system to provide participants with \$25 Wal-Mart gift cards while honoring the IRB and the Accounting Offices requirements, maintaining a supply of screening tools and interview packets, organizing interviews at multiple sites, and training interviewers on the research teams. To pay participants a small incentive required some negotiations. We wanted to protect the confidentiality of participants' as established by our IRB and manage the requirements of the Accounting Office; therefore, we had placed the same identification numbers on receipts and survey packets, interviewers signed their names on the receipt, and participants placed their initials on the receipt indicating receipt of the gift card. A statement was added indicating that all gifts of $\$ 500$ or more had to be reported.

Because there were multiple research teams and collaborators were assisting with identifying potential participants, a screening tool became inevitable. We also developed different approaches to obtain a sample of displaced aging adults from New Orleans and the surrounding areas as compared to securing a sample of longterm residents of Baton Rouge. To reduce the likelihood of getting participants who did not meet the research criteria included in the NSF grant and after the 1st day of scheduling multiple interviews, researchers revised flyers, made screening tools for our collaborators, and developed color-plotted posters. In some instances, sign-up sheets were used to make sure that there were enough study volunteers and interviewers. A primary investigator met or called organizations to ensure communications were clear, but communications were taxed throughout the process.

Multiple interviews were scheduled on specific dates at specific locations, although interviewers also scheduled interviews at other times and at other locations. At least one primary investigator would come to Louisiana 2 days or 1 week before the scheduled dates. This person worked with agencies to screen participants, doubled check pre-screened participants, and placed signs and flyers up to announce the scheduled interview date, time slots, locations, and available number of slots for each time frame. The research team reached their desired number of interviews while respecting the time and needs of study participants. Oftentimes participants had appointments with insurance or mortgage companies, health care professionals, and social service agencies. If they did not have a personal vehicle, they had to rely upon taxis, buses, neighbors or friends to keep those appointments. Having an interview schedule allowed them to tell us their availability and it reduced the likelihood that only home-bound displaced persons, especially those in the trailer and senior residence, participated in the study. Based on one of the first scheduled experiences conducting multiple interviews in one 
location, the primary investigators attempted to determine if enough trained interviewers were available to conduct multiple interviews in set time blocks. For example, three or four interviews would be scheduled at 8:00, 11:00, 1:00, and 3:00.

In fact, three to four training sessions for graduate students and caseworkers in aging agencies were held over the course of 6 months. The multiple training sessions were largely a response to high turnover of research team members due to student graduations, conflicting academic and research schedules, burnout, and timing issues. Some interviewers were non-residents and failed to fully understand the culture, age-related behaviors, and terms used by study participants; Yet, others were skillful and established rapport with participants. For example, participants might use this polite Southern statement of "you aren't from here," indicating communication or rapport glitches. Hiring caseworkers from a local agency reduced issues related to cultural incompetence; they collected approximately $1 / 3$ of the data.

Summary On the one hand, having one primary investigator in the affected areas, conducting research in a disaster-ridden area, and having collaborators in the affected area-some of whom were victims of Katrina, contributed to the initial lag in the interview start time. Compassion fatigue, a historical artifact, created problems with completing interviews with long-term residents of Baton Rouge. In addition to the IRB requirements, FEMA clearance was required, which included having a public relations officer shadow the research team because pictures were being taken. Administrative challenges included but were not limited to finding an approach to pay participants a small incentive, protecting their confidentiality as required by the Institutional Review Board and creating an effective audit trail as required by the Accounting Office screening potential.

On the other hand, gaining entry was enhanced by having one primary investigator from the area and building collaborations with local agencies and faithbased institutions. These collaborative relationships also allowed the convenience sampling team to collect their data over a 6-month period. To effectively administer the data collection process and clearance processes, one primary investigator met with FEMA and other collaborators before data were collected at the trailer communities, senior centers, or senior housing centers. Safety concerns were reduced by FEMAs commitment and willingness to escort interviewers and to post a guard at the community tent or trailer. Hiring caseworkers from local agencies reduced issues related to cultural competence. For each interviewer, the first three interviews were carefully monitored, caseworkers were shadowed to make sure that they understood the instrument, and regular updates and concerns were sent to the entire team to maintain quality control.

\section{Purposive Sampling}

To capture the experiences of diverse groups and unveil racial and economic disparities, another team employed a combination of quantitative and qualitative methods to analyze the spatial, socioeconomic, and psychological consequences of Hurricane Katrina and its aftermath on Vietnamese American and African American 
residents in an easternmost New Orleans suburb (SGER \#0555135 and SGER \#0555086). According to the U.S. Census (2000), African Americans and Vietnamese Americans accounted for $50.9 \%$ and $43.3 \%$ of the total population, respectively in the study area. Among Vietnamese Americans, 32.5\% were foreignborn, and $36.7 \%$ of households were identified as linguistically isolated. Based on this demographic profile, they targeted Vietnamese Americans or African Americans 18 years old and older who lived in the study area prior to Katrina.

Purposive sampling has been applied in research that targets one or more specific predefined groups, such as Vietnamese Americans and African Americans who lived in two identified census tracts in New Orleans prior to Katrina. Purposive sampling is potentially a very effective method for research that aims to understand and obtain information from a target population and where sample representativeness may not be the primary concern (Trochim 2006). The disadvantage is that responses from accessible subgroups in the target population might be overweighted (Trochim 2006). There are several different approaches to purposive sampling, such as snowball sampling (Bailey 1994). When working with vulnerable communities, snowball sampling may be a more appropriate way to recruit hard-toreach populations, particularly in the post-disaster context. Working with community leaders also proved to be effective in reaching the target population (Flaskerud and Winslow 1998).

\section{Survey Recruitment Challenges}

We planned to recruit 208 (104 each Vietnamese and African American) adult residents aged 18 and above from the study area or areas of their relocation. Learning from previous experiences of working with communities with ethnically diverse groups, the primary investigators first contacted community faith-based organizations because of the central role these institutions play in local social networks (for example see Billingsley 1992; McAdoo 2006). While the residential space of both Vietnamese and African Americans often overlap, the role of their respective faith-based social networks operates very differently. The challenges of recruiting Vietnamese and African Americans are given separately in the following sections.

Vietnamese Americans Given the deep and multiple roles played by the ethnicVietnamese Catholic parish in the daily lives of community residents, we first contacted church leaders, as well as social service providers in early December 2005 to establish trust. (See Table 3 that outlines the study administration.) During this first fieldtrip, we interviewed community leaders and consulted with them to determine the most culturally appropriate method for recruitment in the postdisaster context. The sampling plan was developed based on the distinctive individual and community characteristics and resources to maximize internal and external validity of study results. Thus, purposive sampling was used because it is more realistic and feasible for recruiting a highly mobile population in the postKatrina context. The purposive sample team also recruited Vietnamese American participants through snowball sampling; this technique proved to be very effective 
Table 3 Purposive sampling study administration

\begin{tabular}{|c|c|}
\hline Time frame & Activities \\
\hline $\begin{array}{l}\text { November- } \\
\quad \text { December } 2005\end{array}$ & $\begin{array}{l}\text { Finalized survey, interview and focus group questions and other study materials } \\
\text { including consent and incentive forms, screening form, flyer, cover letter, etc. } \\
\text { All study materials were translated into Vietnamese and back-translated into } \\
\text { English } \\
\text { Recruited research assistants and community liaisons; developed training packets } \\
\text { for team members } \\
\text { Contacted faith-based and service institutions for collaboration opportunities } \\
\text { Developed electronic library for Katrina related media reports }\end{array}$ \\
\hline January 2006 & $\begin{array}{l}\text { Conducted pilot test of survey questions on five Vietnamese Americans and five } \\
\text { African Americans to ensure linguistic and cultural appropriateness } \\
\text { Modified survey questions based on the pilot test results } \\
\text { Trained research team members for study materials administration } \\
\text { Arranged space and time for data collection }\end{array}$ \\
\hline February 2006 & $\begin{array}{l}\text { Conducted survey and in-depth interviews in the study area after receiving IRB } \\
\text { approval from Arizona State University and Ball State University (first field } \\
\text { trip) } \\
\text { Created databases for survey and interview data }\end{array}$ \\
\hline March 2006 & $\begin{array}{l}\text { Pilot tested focus group questions } \\
\text { Refined focus group questions } \\
\text { Conducted two focus groups (one each Vietnamese and African American) in } \\
\quad \text { Houston (second field trip) }\end{array}$ \\
\hline April-July 2006 & $\begin{array}{l}\text { Continued to collect survey data and conducted in-depth interviews with identified } \\
\text { key informants (e.g., religious leaders, health care providers, social service } \\
\text { providers) } \\
\text { Conducted the } 3 \text { rd and } 4 \text { th field trips to access returned rate and business re- } \\
\text { opened rate } \\
\text { Transcribed and translated qualitative data from survey questionnaires, focus } \\
\text { group, and interviews } \\
\text { Presented preliminary survey data in conferences } \\
\text { Prepared one invited book chapter }\end{array}$ \\
\hline $\begin{array}{l}\text { August-November } \\
\quad 2006\end{array}$ & $\begin{array}{l}\text { Conducted the } 5 \text { th field trip } \\
\text { Continued data analysis and conference presentations }\end{array}$ \\
\hline $\begin{array}{l}\text { December 2006- } \\
\text { present }\end{array}$ & $\begin{array}{l}\text { Conducted the 6th field trip } \\
\text { Continued data analysis and conference presentations } \\
\text { Prepared and submitted annual report and seven manuscripts }\end{array}$ \\
\hline
\end{tabular}

in the highly cohesive group in part because they evacuated and returned on a multifamily basis. They also visited owners of re-opened businesses in the community and requested that they recommend potential participants, including community members who had not yet returned to the community.

The current research team worked collaboratively with church and community leaders to recruit survey participants during the annual weekend long Vietnamese New Year Tet celebration held on church grounds in February 2006. The celebration was well attended by those who had permanently returned to the community as well 
as by those still living with family elsewhere in the New Orleans metropolitan area (MSA) or in neighboring states. To assure sample diversity, the research team members paired with Vietnamese speaking research assistants to recruit community residents who speak no or limited English. All participants received a small cash incentive put in red envelopes, a symbol of "lucky money" in Vietnamese New Year cerebration, which proved to be a culturally appropriate and effective way to increase participation rates. Approximately, 68\% of planned sample size for the Vietnamese American group and 7\% for the African American group was obtained during this single event and very little missing responses $(<2 \%)$ on the survey questions were found.

African Americans To recruit African American participants, the purposive sampling team collaborated with service providers from the study area and a nonprofit social organization in Houston, TX that were assisting with tax and disaster relief among Katrina survivors who evacuated to Houston. This provided an opportune environment to recruit participants; approximately $42 \%$ of planned sample size for the African American group was recruited through this event. Given the low return rate of the African American group, the team also engaged in door-todoor canvassing in the neighborhoods in which African Americans comprised a significant percentage of the population. Care was taken to recruit participants from various neighborhoods to reduce the possibility of spatial bias (McGrew and Monroe 1993). Access to potential participants, however, was limited to weekends. Nevertheless, approximately $20 \%$ of planned sample size for the African American group was obtained through this method. Another method to reach potential sample size was to personally contact parents of children visiting for a Saturday parentteacher conference in November 2006, with permission of a community charter school principal.

The challenges of recruiting African American participants were far greater for a variety of reasons. First, the critical role of faith-based organizations in contacting survey participants proved less rewarding. Unlike Vietnamese Americans whose church attendance is almost exclusively centered on the single large Catholic church in the community, African American attendance was focused on geographically scattered churches outside the community. One mega-like church located in New Orleans East that African Americans in the community attended was relocated to Atlanta, Georgia because of flood damage. While this church welcomed inquiries from the research team, it was unable to provide names and addresses of evacuated church members. In addition, one exclusively African American Baptist church in the community had yet to re-open by July 2006 and attempts to contact the pastor were unsuccessful.

African American participants returned to the study area at lower rates compared to Vietnamese Americans, which represented a second challenge. Approximately $40 \%$ of African Americans in the two census tracts resided in three low income apartment complexes, and by November 2006 these complexes had yet to re-open. This was an additional challenge for us to recruit lower-income African American residents. In addition, African American homeowners only began returning to the 
community in March and April 2006, 2-3 months later than Vietnamese American homeowners. Purposive sampling was not as effective with African Americans as with Vietnamese Americans in the study because the African American social network structure was more fragmented, especially after Hurricane Katrina.

\section{Research Strategies and Concerns}

Coupled with some effective strategies, this team faced inherent research challenges as they worked in the midst of a crisis caused by a hurricane. One strategy was that one team member possessed over one decade of research experience in the community, which obviated many of the inherent barriers to conducting research in a new socio-cultural environment. The approach of collaborating with service agencies and community leaders with the explicit intent of being partners in the rebuilding process was well received. Additionally, rigorous and culturally appropriate procedures for sample recruitment and instrument development enhanced internal and external validity of the study results.

Looking at the challenges, it turned out that a shortcoming was the fact that snowball sampling was better suited to Vietnamese Americans than African Americans. Additionally, while the team had a Vietnamese American research assistant who lived in the study area, no team members lived in New Orleans, and this necessarily required substantial lead time to plan and coordinate data collection trips. Availability of a centralized database for researchers to track disaster survivors may significantly decrease the burden of locating a highly mobile population in the post-disaster context and enhance validity of study findings.

\section{Conclusions}

Using different sampling strategies, the current studies provide insights into effective strategies and illuminate research challenges, giving additional insight into disaster research. The four sampling strategies-census, stratified random, convenient, and purposive-were used in other disaster studies (for a summary see Norris 2005). For the census team, the post-disaster context posed special challenges to survey methodology. The study location was not known beforehand and the research design must be developed and implemented quickly without having all knowledge of the situation. For this team, the spatial distribution of the population was different before and after the disaster. These challenges have operational and analytical implications specific to an emergency or disaster setting.

The attempt to conduct in-person interviews in Mode 1 of the study using a stratified random sample was not fully realized. This team revised their strata to include non-flooded and flooded streets in census tracts. Securing a sufficient sample size in an area devastated by high winds and water undermined researchers' safety, difficulty contacting potential participants, and the inability to assign standard disposition codes were among the challenges-representing survey error related to sampling error and sample size. The storm-ravaged area was hard to 
navigate and administrative duties were increased because the university was in the affected area of Katrina.

Looking at the convenience and purposive sampling teams, some general themes are worth noting. For the convenience sample group, the enhanced problems faced when conducting disaster research largely involved research collaborations, clearance requirements that went beyond the IRB, and additional administrative duties. The purposive sample group learned that the importance of having someone living in the affected area and who used culturally - appropriate research practices to ensure that the sample reflected the two identified groups-Vietnamese and African American by modifying their sampling procedures.

\section{Unique and Common Characteristics}

All teams engaged in training, yet the use of collaborators and students required additional training sessions by the convenience sampling team. Each engaged in some modification of their sampling or research procedures based on the conditions that resulted from Hurricane Katrina. Adjusted sampling strategies included the use of supplementary samples and some reconfigurations of the data collection area by the census group. Cell phone interviews replaced in-person ones, a modification necessary to gain a sufficient random, stratified sample. The multiple approaches in the purposive sampling allowed one group to survey the group hardest to reach.

As we revisit unique and common characteristics, some differences are worth noting. The multi-disciplinary nature of the teams, an insightful requirement by the National Science Foundation, served to enhance the methodological strategies. One team, for example, noted how the interdisciplinary team supported the use of combined methods. In fact, both of the non-experimental design teams used combined methods. While safety was of concern to the census and stratified random sample group, it was less of concern to the convenience sample team. Having someone in the affected area was useful to three of the four teams, but the purposive sampling team recognized the need to have a research assistant living in the affected study who possesses an insiders knowledge of community culture and requisite research skills. As noted by the convenience sampling team care must be taken when engaging individuals and agencies who have been directly, as well as professionally and personally affected by the disaster. The projects that used experimental designs, census and stratified random sampling, faced challenges with locating the census tract and finding inhabitants. Yet, the non-experimental groups faced similar challenges, demonstrating that sampling error and bias continues to be a major concern when conducing disaster research. Regardless of the sampling strategy, the added challenges to the research process included the temporal context related to the impact of a natural and technological disaster and an overburdened affected area.

\section{Recommendations}

The importance of adhering to excellent social science practices was reinforced as all teams indicated the importance of piloting their instrument to reduce sampling 
error or modifying the procedures to acquire the best possible random, stratified, convenient, or purposive samples. Future teams may be able to better plan for administrative challenges, which include but is not limited to obtaining IRB approval to pay participants and call centers is warranted. FEMA authorization was needed to protect study participants and to promote the safety of study participants and the research team. Realistic use and expectations of collaborative relationships requires additional thought when planning to conduct disaster research. Having someone familiar with cultures and disasters in the affected area was one of the most useful strategies for disaster research.

Based on the lessons learned from these four disaster research projects, scientists would need to attend to sampling error, coverage error, and measurement and nonresponse error. Other threats to internal validity, such as history and maturation were important items to plan for when conducting disaster research. To address the lack of participants in the affected census tracts, sampling error was managed by using random start and cluster sampling. Replacement and supplemental samples were used to address coverage error. Reducing the number of days spent in the field allowed the census study team to systematically complete "call-backs," pick up completed forms, and to leave "mail-back" survey packets. The team using stratified random samples had to refrain from using readily available flood maps and data to select their participants; consequently, they revised their stratum to include flooded and non-flooded areas based on less precise data.

A significant consideration for scholars is determining the best sampling strategy, and this consideration is heightened when conducting disaster research. Consequently, the current manuscript outlines the sampling and methodological challenges and useful approaches used by four research teams; however, additional research is warranted. There is a need for a review of best practices in disaster research and to duplicate and modified Norris' (2005) work. Comparing methodological approaches for disaster studies in the U.S. and other countries may prove useful. In sum, these four projects indicate that administrating and conducting disaster research is intensified-but it is not impossible.

Acknowledgments The authors would like to thank other contributors to this manuscript. Additional regard goes to RAND Corporation and the National Science Foundation for their vision for and support in developing manuscripts on methodological challenges in the midst of a natural disaster. This material is based upon work supported by the National Science Foundation. Any opinions, findings, and conclusions or recommendations expressed in this material are those of the author(s) and do not necessarily reflect the views of the National Science.

\section{References}

American Association for Public Opinion Research. (AAPOR). (2004). Standard definitions: Final dispositions of case codes and outcome rates for surveys. Lenexa, KS: AAPOR.

Bailey, K. D. (1994). Methods of social research. New York: The Free Press.

Billingsley, A. (1992). Climbing Jacob's ladder: The future of African American families. Mahweh, NJ: Simon and Schuster.

Blumberg, S. J., Luke, J. V., \& Cynamon, M. L. (2006). Telephone coverage and health survey estimates: Evaluating the need for concern about wireless substitution. American Journal of Public Health, 96, 926-931. 
Bride, B. E. (2004). The impact of providing psychosocial services to traumatized populations. Stress, Trauma and Crisis: An International Journal, 7(1), 29-46.

Brodie, M., Welzien, E., Blendon, R. J., \& Benson, J. M. (2006). Experiences of Hurricane Katrina evacuees in Houston shelters: Implications for future planning. American Journal of Public Health, 96, 1402-1408.

Bronfenbrenner, U. (1986). Ecology of the family as a context for human development: Research perspectives. Developmental Psychology, 22, 723-742.

Campbell, D. T., \& Stanley, J. C. (1963). Experimental and quasi-experimental designs for research. Chicago, IL: Rand McNally College Publishing Company.

Dillman, D. A. (2000). Mail and internet surveys: The tailored design method (2nd ed.). New York: John Wiley.

Durant, T., Collins, S., \& Rodgers, H. (2006). Unanswered questions: Families in the aftermath of natural disasters. Presentation given at the 2006 Annual Conference of the National Council on Family Relations, Minneapolis, MN.

Elder, G. (1977). Family history and the life course. Journal of Family History, 2, 279-304.

Figley, C. (2006). Compassion fatigue: An expert with Charles R. Figley. Retrieved on 26 March 2007 from http://www.medscape.com/viewarticle/513615_print.

Flaskerud, J. H., \& Winslow, B. J. (1998). Conceptualizing vulnerable populations health-related research. Nursing Research, 47(2), 69-78.

Gibson, M. J., \& Hayunga, M. (2006). We can do better: Lessons learned for protecting older adults in disasters. Washington, DC: American Association for Retired Persons.

Groves, R. M., Fowler, F. J., Jr., Couper, M. P., Lepkowski, J. M., Singer, E., \& Tourangeau, R. (2004). Survey methodology. Hoboken, NJ: John Wiley and Sons.

Hummer, R., Fischer, O., \& Masters, R. (2005). Proposal for a survey of adult Katrina refugees in Austin, Texas, 2005. Unpublished manuscript. Population Research Center, Department of Sociology, University of Texas at Austin.

Kish, L. (1965). Survey sampling. New York City, NY: John Wiley and Sons.

Lavrakas, P. J., \& Shuttles, C. D. (2005). Cell phone sampling. Summit ii statements on accounting for cell phones in telephone survey research in the U.S. Nielsen media research. Retrieved on 1 August 2007 from http://poq.oxfordjournals.org/cgi/reprint/nfl040v1

Leon, A. M., Altholz, J. A. S., \& Dziegielewski, S. F. (1999). Compassion fatigue: Considerations for working with the elderly. Journal of Gerontological Social Work, 32(1), 43-62.

McAdoo, H. P. (Ed.). (2006). Black Families (4th ed.). Newbury Park, CA: Sage.

McGrew, J. C., Jr., \& Monroe, C. B. (1993). An introduction to statistical problem solving in Geography. Dubuque, IA: William C. Brown.

Norris, F. H. (2005). Disaster research methodology: Past progress and future directions. Retrieved on 15 December 2006 from http://www.redmh.org/research/general/REDMH_methods.pdf.

Oregon Survey Research Laboratory. (2007). Northwest area foundation social indicators survey: September-December 2003. Retrieved on 15 January 2007 from https://scholarsbank.uoregon.edu/ dspace/bitstream/1794/1013/1/NWAF+AAPOR+Outcome+Rate+Documentation.pdf.

Public Opinion Laboratory. (2007). Research standards: Calculating responses rates. Retrieved on 15 January 2007 from http://www.pol.niu.edu/response.html.

Roberts, S. B., Flannelly, K. J., Weaver, A. J., \& Rigley, C. R. (2003). Compassion fatigue among chaplains, clergy, and other respondents after September 11th. Journal of Nervous and Mental Disease, 191(11), 756-758.

Swanson, D. (1982a). "Municipal Census Results and Costs for 1981" in Alaska Population Overview: 1981. Juneau, Alaska: Alaska Department of Labor.

Swanson, D. (1982b). "State population estimates for Alaska during the 1970's" in Alaska Population Overview: 1981. Juneau, Alaska: Alaska Department of Labor.

Swanson, D. (1982c). “1981 Population determinations, technical documentation” in Alaska Population Overview: 1981. Juneau, Alaska: Alaska Department of Labor.

Swanson, D. (1983a). Special census results for oil-related worksites in the North Slope Borough. Alaska Economic Trends, 3(March), 104.

Swanson, D. (1983b). "Population determination: Technical documentation" in Alaska Population Overview: 1982. Juneau, Alaska: Alaska Department of Labor.

Swanson, D. (1997). The 1997 "Biosphere" food consumption survey: Summary findings and technical documentation. U.S. Department of Energy, Office of Civilian Radioactive Waste Management 
(DE-AC01-91RW00134) (November, 1997). Las Vegas, Nevada: U.S. Department of Energy, Yucca Mountain Project.

Swanson, D., Carlson, J., \& Williams, C. (1990). The development of small area socioeconomic data to be utilized for impact analysis: Rural Southern Nevada. In High level radioactive waste management: Proceedings of the 1990 International Conference, American Nuclear Society and American Society of Civil Engineers, New York, New York, pp. 985-990.

Trochim, W. M. (2006). Nonprobability sampling. Retrieved 25 October 2006 from http://www.social researchmethods.net/kb/sampnon.htm or http://unstats.un.org/unsd/demographic/meetings/egm/ Sampling_1203/docs/no_5.pdf.

U.S. Census. (2000). American FactFinder. Retrieved on 10 July 2005, from http://factfinder.census.gov/ home/saff/main.html?_lang=en.

U.S. Department of Labor. (2005). Effects of Hurricane Katrina on local area unemployment statistics. Retrieved on 7 June 2007 from http://www.bls.gov/katrina/lausquestions.htm. 